\title{
0 processo de ensino e aprendizagem do esporte na escola na perspectiva dos professores de Educação Física
}

\author{
The process of teaching and learning sports in school on the \\ perspective of physical education teachers
}

Marcelo José Taques, ${ }^{1}$ Silvia Christina de Oliveira Madrid

'Universidade Estadual de Ponta Grossa, Guarapuava, PR, Brasil.

Recebido em: 29/01/2017 / Aceito em: 24/05/2017 / Publicado em: 30/06/2017

taques18@yahoo.com.br

\section{RESUMO}

Este artigo tem por desígnio apresentar um recorte da pesquisa realizada junto ao Programa de Pós-Graduação Mestrado e Doutorado em Educação da UEPG/PR e do grupo de estudos e pesquisas em educação física escolar e formação de professores - GEPEFE/CNPq. Objetivo: evidenciar alguns elementos básicos sobre os saberes e estratégias que os professores apresentam sobre o esporte e as ferramentas que podem ser adotadas com esse conhecimento, durante as aulas de Educação Física, nos anos finais do ensino fundamental. Método: a pesquisa é qualitativa com delineamento pautado na pesquisa de campo; utilizamos como instrumento para a coleta de dados o questionário aberto, destinado a todos os professores de Educação Física de duas instituições de ensino públicas estaduais do município de Guarapuava-PR. A técnica de análise de dados foi pautada na Análise de Conteúdo, a partir da delimitação da categorização, a qual foi desenvolvida a partir do agrupamento e da seleção das respostas que apresentavam semelhanças e significados relevantes para a reflexão da temática. Resultados: buscamos contribuir com reflexões, discussões e possíveis ações docentes para o ensino do esporte na escola, numa perspectiva pedagógica, bem como valorizar o processo de pesquisa que possibilitem novos estudos à luz do desenvolvimento do esporte no contexto escolar, uma vez que observamos que as práticas docentes são abordadas de diversas maneiras. Considerações finais: um processo de reflexão sobre as práticas pedagógicas vem sendo desenvolvido no contexto do ensino fundamental; dessa forma, torna-se necessário uma sistematização do conhecimento e uma análise criteriosa na organização das estratégias metodológicas que podem ser adotadas.
Palavras-chave: Esporte na escola; Estratégias de Ensino; Intervenção Docente.

\section{ABSTRACT}

This article aims to present a research report carried out with the Postgraduate Program in Education of Ponta Grossa state university (UEPG), state of Paraná (Brazil) and the group of studies and research in school physical education and teacher training - GEPEFE / CNPq. Objective: to highlight some basic elements about the knowledge and strategies that teachers present about the sport and the tools that can be adopted with this knowledge during Physical Education classes in the final years of elementary school. Method: the research is qualitative, with a delineation based on field research. We used as an instrument for data collection the open questionnaire for all physical education teachers of two state public education institutions in the city of Guarapuava, state of Paraná (Brazil). The data analysis technique was based on Content Analysis from the delimitation of categorization which was developed from the grouping and the selection of the answers that presented similarities and significant meanings for the reflection of the thematic. Results: through this article we seek to contribute with reflections, discussions and possible teaching actions for the teaching of sports in the school in a pedagogical perspective, as well as to valorize the research process that make it possible new studies in the light of the development of sports in the school context, since the teaching practices are approached in different ways. Closing remarks: they pointed to a process of reflection on the pedagogical practices that have been developed in the context of elementary 
education. It becomes necessary a systematization of knowledge and a careful analysis in the methodological strategies organization that can be adopted.

Keywords: Sport at School; Teaching Strategies; Teacher Intervention.

\section{INTRODUÇÃOO}

Este estudo é um recorte da pesquisa realizada e concluída junto ao Programa de Pós-Graduação Mestrado e Doutorado em Educação da UEPG/PR e do grupo de estudos e pesquisas em educação física escolar e formação de professores - GEPEFE/CNPq. O artigo apresenta como objetivo, evidenciar alguns elementos básicos sobre os saberes e estratégias que os professores apresentam sobre o esporte e as ferramentas que podem ser adotadas com esse conhecimento, durante as aulas de Educação Física, nos anos finais do ensino fundamental.

Justificamos pelo fato de contribuirmos para a comunidade acadêmica da área no sentido de compreender as especificidades do esporte e suas possibilidades de intervenção nos anos finais do ensino fundamental, pois, diante do debate sobre o esporte, percebemos sua ampla heterogeneidade e seus diversos cenários e formas de manifestações. Nesse sentido, o campo esportivo apresenta por meio das diversas formas de expressão, suas semelhanças e diferenças nas disposições do esporte moderno. Assim, nosso intuito é evidenciar o esporte como um conteúdo polissêmico, o qual apresenta suas características próprias em seus cenários, mas que se inter-relacionam diante do processo de formação na escola.

Para que esses elementos se concretizem no contexto da escola, torna-se necessário uma identidade docente que esteja comprometida com o ensino do esporte, no intuito de qualificar seus saberes, tornando-os amplos, e não simplesmente atendendo a lógica estrutural atual em que a escola está inserida. Outro elemento muito importante é o favorecimento e a participação coletiva, durante as ações que serão desenvolvidas na escola, pois o planejamento participativo pode atender de forma mais abrangente as necessidades dos alunos, durante o processo de ensino aprendizagem e nortear as etapas da prática pedagógica.

O objetivo da investigação foi verificar quais os saberes e estratégias que os professores apresentam sobre o esporte e as ferramentas que podem ser adotadas com esse conhecimento, durante as aulas de Educação Física, nos anos finais do ensino fundamental.

Acreditamos que a temática desta pesquisa é relevante para a comunidade acadêmica da área, pois tem a intenção de ampliar as discussões e reflexões acerca do ensino do esporte no contexto escolar, ${ }^{2}$ a fim de que possam colaborar para a cumulatividade e transferibilidade do conhecimento sobre esse conteúdo nas aulas de EF, a partir de uma perspectiva crítica.

\section{MÉTODO}

No intuito de compreendermos a dinâmica existente na intervenção do esporte nas aulas de Educação Física, buscamos sublinhar uma análise do conteúdo es- porte, por meio de seu valor educativo para o processo de ensino-aprendizagem escolar.

Assim, este artigo surgiu a partir das discussões de pesquisadores sobre o referido tema, onde apontam alguns limites e possibilidades de se trabalhar com esse conteúdo no âmbito escolar. Partindo dessa ideia, buscamos assumir o desafio de realizar discussões a partir de alguns pressupostos teóricos, sobre a possível intervenção do professor por meio do esporte, já que a busca por ações metodológicas é uma constante.

Neste sentido, este ensaio se caracteriza como sendo uma pesquisa do tipo qualitativa, que segundo Thomas; Nelson; Silverman, ${ }^{3}$ "busca compreender o significado de uma experiência dos participantes, em um ambiente específico, bem como o modo como os componentes se mesclam para formar o todo". Assim, buscamos através das articulações com os autores, proporcionar ao leitor algumas discussões e reflexões pertinentes, a respeito desta temática, no âmbito escolar.

Para chegarmos a essas discussões e reflexões, o delineamento desse estudo foi fundamentado na utilização de uma pesquisa de campo, utilizando como instrumento para a coleta de dados, o questionário aberto para os professores de Educação Física de duas instituições públicas de ensino público estadual do município de Guarapuava-PR. Vale ressaltar que todos os procedimentos éticos foram adotados, sendo apresentada uma carta de autorização para a direção das escolas e um termo de consentimento livre e esclarecido para os professores de Educação Física para a participação em pesquisa, sendo que esses instrumentos foram apresentados a Comissão de Ética em Pesquisa da instituição de ensino superior para análise e validação. Foi aprovado sob protocolo $n^{\circ} 1.950 .694$.

O questionário além de buscar a identificação e caracterização dos professores, contém treze perguntas que evidenciam o foco da pesquisa, a partir das respostas dos professores sobre: a contribuição de sua formação para o trabalho pedagógico com a Educação Física e o desenvolvimento do esporte. O conteúdo mais abordado nas aulas e as estratégias metodológicas utilizadas, durante o processo de intervenção, a compreensão das manifestações e conceituações entre esporte e jogos e as possibilidades de intervenção por meio da estratégia metodológica do jogo. As informações dos questionários foram apresentadas a fim de manter o sigilo das informações e anonimato dos participantes da pesquisa.

$\mathrm{O}$ processo de análise sobre os questionamentos foram agrupados pela técnica de Análise de Conteúdo ${ }^{4}$ e abordados a partir das seguintes categorias: saberes acadêmicos sobre o esporte: contribuições e estratégias de ensino; conteúdo predominante e estratégias metodológicas utilizadas nas aulas; o jogo como possibilidade de intervenção pedagógica para o ensino do esporte. As categorias foram delimitadas a partir de perguntas realizadas no questionário aberto e que se destacam em cada uma das categorias elaboradas.

As discussões se deram em virtude do confronto entre as respostas dos questionários e a interpretação desenvolvida de acordo com as referências bibliográficas sobre o referido tema. Partindo deste contexto, a intenção dessa investigação, foi proporcionar ao leitor o entendimento sobre as possibilidades de intervenção do 
esporte, enquanto fenômeno educacional, colaborando para a compreensão de mal entendidos, que mobilizam a comunidade acadêmica da área.

Sendo assim, acreditamos estar fornecendo subsídios que possam nos auxiliar em nossas ações docentes e contribuir para a superação de possíveis dificuldades no enfrentamento de novas estratégias metodológicas para o ensino do esporte, buscando valorizar seu caráter educativo, e ainda, contribuir para que novos estudos possam ser desenvolvidos à luz dessa temática, colaborando para a cumulatividade e transferibilidade do conhecimento.

\section{SABERES ACADÊMICOS SOBRE O ESPORTE: CONTRI- BUIÇÕES E ESTRATÉGIAS DE ENSINO}

Por meio dessa categoria buscamos trazer algumas discussões a respeito dos elementos que, de certa forma, foram relevantes para a formação profissional desses professores. As questões que desencadearam as mesmas foram: Quais as contribuições das escolas e da instituição de ensino superior para a sua formação em Educação Física? Quais as estratégias de ensino que foram utilizadas para o trabalho com o esporte, durante a sua formação inicial?

Esses aspectos se tornam relevantes, pois, nos permitem refletir sobre as histórias de vida e experiências dos professores, as quais, ao longo do processo de formação, foram essenciais para a construção de uma identidade profissional docente. No que tange aos elementos que estimularam os sujeitos para a escolha da profissão, percebemos a existência de um consenso entre as respostas que foram determinantes para a escolha profissional.

Nesse processo de identificação dos elementos que contribuíram para os sujeitos da pesquisa em sua escolha profissional, buscamos informações referentes a quanto e como a graduação contribuiu para a sua formação em Educação Física. Sob esses critérios, obtivemos algumas respostas pertinentes para o debate em questão, sendo: Com certeza, foi de grande contribuição à formação acadêmica, pois me deu um embasamento teórico e prático para atuar na escola (P6B); A minha formação contribuiu muito na forma pedagógica de trabalhar com os alunos e no conteúdo científico (P5B); Foi absolutamente essencial, tive grandes mestres que só vieram a acrescentar na minha formação como professor (P1A); Passei a entender que a Educação Física não está apenas ligada ao esporte, e sim abrange muito mais coisas (P3A); Foi imprescindível por fazer entender o verdadeiro papel do professor de Educação Física (P2A).

Essas questões se apresentam como um desafio para os professores, pois a relação entre o pensamento acadêmico (teoria) e a ação pedagógica na escola (prática) são elementos fundamentais para a aquisição de competências e habilidades para o campo de atuação em Educação Física. Diante dessas manifestações dos professores, percebemos que a formação inicial foi essencial para a compreensão de como ser professor, assim como no rompimento das ideias em acreditar que essa área está somente articulada e subordinada ao conteúdo esporte. Entre essas informações que foram colocadas pelos professores, temos duas ma- nifestações que demonstram a relevância de algumas disciplinas e da formação continuada, sendo: Na minha formação tive bons professores, que contribuíram para minha formação, mas a busca do conhecimento deve ser contínua, para o professor melhorar a sua prática (P4B); Meu curso de graduação contribuiu muito, fiz uma matriz curricular de 4 anos em tempo integral, com professores que trabalhavam disciplinas voltadas para a escola, como metodologia de ensino e estágio supervisionado em diversas áreas. No entanto, a formação continuada foi e está sendo imprescindível no entendimento do contexto escolar (P3B).

Essas considerações são importantes, pois nos apresentam a contribuição de algumas disciplinas como Metodologia de Ensino, a partir de suas diversas abordagens pedagógicas e do Estágio Supervisionado, para o contato com a realidade escolar e consolidação dessas estratégias de ensino por meio da práxis pedagógica. Ainda nessas análises dos professores, fica evidente a importância da formação continuada para o entendimento do contexto escolar, sendo essa uma exigência necessária para romper com estratégias ultrapassadas de ensino que valorizam apenas a aptidão/ capacitação física. De acordo com Macedo, 5 "se nós professores, não colocarmos na pauta de nossa vida pessoal e profissional, a questão do aprender continuado, nossa competência de ensinar pode ficar cada vez mais insuficiente, obsoleta".

Nesse sentido, buscando uma compreensão de como o esporte foi trabalhado, durante a formação inicial dos sujeitos da pesquisa, obtivemos algumas informações que nos auxiliam a refletir sobre as possibilidades e limitações das estratégias de ensino que vem sendo utilizadas no tratamento do esporte, enquanto conteúdo, sendo: $O$ esporte foi abordado numa maneira mais ampla, tive que aprofundar meus estudos para melhorar a minha prática em âmbito escolar (P4B); Nossa grade trouxe os esportes separadamente, vimos fundamentos, histórico, regras, enfim, conhecemos um pouco de cada modalidade esportiva (P1B); Foi dividido em disciplinas (P6B); Todos os esportes em geral (P2A).

O esporte como já mencionado, apresenta muitas dimensões que no processo de ensino aprendizagem podem se articular conforme estudos de Bracht ${ }^{6}$ e Tubino, ${ }^{7,8}$ pois o objetivo, além de estabelecer essas especificidades de cada tipo de manifestação, é contribuir para seu entendimento de forma multicultural, já que um mesmo tipo de esporte pode ser apropriado pelos alunos de diferentes maneiras. No entanto, a partir dessas considerações, percebemos que o conteúdo esporte foi abordado de forma isolada, não sendo desenvolvido a partir de suas diferentes manifestações e possibilidades de aproximações.

Por meio dessas variadas formas de pensar o esporte na escola, o processo de formação pode ser mais significativo, pois visa uma articulação entre o saber científico com as diversas perspectivas de pensar e experimentar o esporte no contexto social, que possam ir além das dimensões técnicas que são exigidas no esporte de rendimento. Dessa forma, não basta apenas dominar a técnica, a tática, reconhecer as regras de tal modalidade, sem uma devida reflexão sobre as diversas formas de pensar esse fenômeno, a partir de suas diferentes manifestações. Por meio de outra ótica, per- 
cebemos nas respostas de alguns professores algumas estratégias diferenciadas no tratamento dispensado ao ensino do esporte para o âmbito educacional, são elas: Sistematizado da mesma forma que são aplicados nas escolas, o ensino é dividido em partes padronizadas do mais simples ao mais complexo (P1A); Foi trabalhado a maioria dos esportes, mostrando como ensinar o conteúdo em sala (P3A); O conteúdo esporte foi trabalhado de modo que ele fosse aplicado no meio escolar e sendo mais lúdico (P5B); O conteúdo esporte foi trabalhado intensamente, pois tínhamos um ano voltado para o rendimento e um ano voltado para a escola. Exemplo: handebol 1 (rendimento) e handebol 2 (escola) (P3B).

Essas estratégias vivenciadas por esses profes sores nos permitem refletir sobre algumas atitudes adotadas para a transmissão do conhecimento sobre o esporte, a partir de uma intervenção que é desenvolvida do saber mais simples ao mais complexo, porém, percebe-se que o ensino ainda continua sendo dividido em partes, os quais apresentam uma relação restrita com a dimensão técnica.

Já, na opinião do terceiro professor, fica evidente que o processo de como esse conteúdo pode ser ensinado, segue uma perspectiva educacional que valoriza o caráter da ludicidade que pode estar articulada aos diversos debates que compõe o campo de estudos sobre a pedagogia do esporte.

E por último, a exposição de que o esporte foi trabalhado de maneira intensa por meio das dimensões do esporte de rendimento e do esporte educacional, já que o processo de formação dessa professora englobava a unificação entre bacharelado e licenciatura. Essa relação se torna relevante, pois apresenta as diversas possibilidades e limitações perante o trabalho com o esporte em seus diferentes contextos, com suas especificidades distintas e seus objetivos próprios, mas que de certa forma contribuem para uma compreensão mais heterogênea do fenômeno esportivo.

\section{CONTEÚDO PREDOMINANTE E ESTRATÉGIAS METO- DOLÓGICAS UTILIZADAS NAS AULAS}

Por meio dessas discussões buscamos apontar os conhecimentos que os professores desenvolvem em suas aulas e que compõe o planejamento e a organização curricular dessa área do conhecimento, assim como, as estratégias metodológicas que são utilizadas no processo de ensino e aprendizagem. Para isso, delimitamos essa categoria a partir dos seguintes questionamentos: Quais conteúdos você busca selecionar e sistematizar, durante suas aulas de Educação Física? Por quê? e Quais estratégias metodológicas são adotadas para o trabalho com o conteúdo esporte em suas aulas de Educação Física nos finais do ensino fundamental? Por quê? Essas informações são relevantes, pois nos apresenta a realidade da EF no âmbito escolar referente ao trabalho com o esporte no ensino fundamental, no entanto, a pesquisa evidencia-se a partir de um estudo singular de algumas realidades, o qual nos traz subsídios relevantes sobre o tratamento pedagógico que é direcionado ao conteúdo esporte nas aulas de EF.

Sabemos que a Educação Física no contexto da escola passou por várias transformações e mudanças que destacava por meio de seus conteúdos primeira- mente a predominância da ginástica e em seguida para atender aos interesses e necessidades de cada época, o esporte passa a ser o conteúdo predominante da Educação Física na escola.

O esporte exerce uma ampla influência na sociedade e na escola, cujo contexto é o foco de nossa pesquisa, pois como nos relata Silva; Bracht, ${ }^{9}$ nas "décadas de 1960, 1970 e 1980 e grande parte da década de 1990, cristalizou-se nas escolas brasileiras uma determinada prática pedagógica em Educação Física, em que configurou-se certa tradição, razão pela qual denominamos a mesma aqui de Educação Física tradicional".

Por meio dessas considerações, podemos perceber a noção de historicidade diante do campo da Educação Física, cuja metodologia de intervenção, pautada em uma perspectiva tecnicista, visava o rendimento e a padronização dos movimentos por meio do esporte, inclusive no contexto educacional, já que naquele período, o ensino era visto como uma maneira de formar mão de obra qualificada, ou seja, "para essa [aquela] nova sociedade, tornava-se necessário 'construir' um novo homem: mais forte, mais ágil, mais empreendedor".10 Atualmente, pensando no trabalho com a Educação Física na escola, buscam-se novas metodologias de intervenção, que possam romper com essa ideia de valorizar somente as perspectivas hegemônicas do esporte ou de esportivização das aulas de uma forma singular e superficial.

Sabemos que a cultura corporal enquanto objeto da EF escolar, apresenta várias formas de expressão e saberes que são determinantes para o entendimento e compreensão dessa área do conhecimento. No entanto, por meio das informações obtidas pelos professores a respeito do conteúdo mais abordado nas aulas, percebemos uma hegemonia do esporte nas aulas de Educação Física. As práticas esportivas, Educação Física e saúde (P3A); A prática esportiva, pois é a base da educação física (P2A); Sempre trabalho mais os "4 bols", pois dentro dos mesmos em sua aprendizagem podemos trabalhar lateralidade, cognitivo, cooperativismo, etc. No ensino médio algo voltado para parte da anatomia e fisiologia (P1A); Nas minhas aulas procuro proporcionar a vivência de vários esportes para os meus alunos (P4B); Todos os esportes. Tanto os novos como o badminton, para que conheçam regras e como se prática, muitos não sabem o que é (P2B); O conteúdo que eu mais trabalho é o esporte da escola. Ė o conteúdo que mais retorno se tem dos alunos, pois eles têm grande influência através da mídia e no seu dia a dia (P5B).

Percebemos a partir dessas considerações que a Educação Física está subordinada ao conteúdo esporte por meio de diferentes perspectivas dos docentes, devido à abrangência de significados que o mesmo representa, enquanto fenômeno sociocultural e pelo possível envolvimento que ambos incorporam por meio dos diferentes aparatos técnicos de informação.

No entanto, vale ressaltar que nossa intenção não é estabelecer uma crítica ao esporte, mas evidenciar quais metodologias são utilizadas no trato desse conhecimento, nas aulas de Educação Física, para que as mesmas não se configurem em uma mera reprodução dos métodos tradicionais que priorizam somente a técnica e o rendimento esportivo. Esse debate já vem sendo desenvolvido por alguns estudiosos como Bracht $^{11}$ e Vago, ${ }^{12}$ sobre o esporte "da/na" escola, cuja 
preocupação é estabelecer um diálogo que apresente de forma clara o entendimento sobre esse conteúdo em seus diversos contextos.

Nesse sentido, ressaltamos que, além da necessidade de o professor contextualizar e tornar significativos os conteúdos, é fundamental a presença de um planejamento que possa balizar o trabalho pedagógico no processo de intervenção. A seleção, organização e sistematização dos conteúdos são elementos necessários para uma prática pedagógica fundamentada nos princípios e valores de uma sociedade democrática, porém, essa seleção e organização, não podem ser efetivadas de forma arbitrária ou incoerente com a realidade e necessidade dos alunos, pois, caso atenda a essas configurações de acordo com Sobrinho: ${ }^{13}$

A escola, com seus mecanismos internos, pode confirmar e consolidar um processo de exclusão do acesso aos bens socialmente produzidos. E faz isso quando nega conteúdos, burla o tempo pedagógico e desenvolve sistemáticas de avaliação voltadas para seleções dos mais altos, mais fortes e mais velozes, eliminando os demais.

Portanto, a organização dos conteúdos que compõe o currículo escolar, o tempo pedagogicamente necessário para a aprendizagem, as estratégias metodológicas e os critérios utilizados para a avaliação são elementos indispensáveis para pensarmos em uma intervenção que possam ir além da reprodução de elementos conservadores no tratamento pedagógico do conteúdo esporte nas aulas de Educação Física. Assim, "não sendo mesmo possível à escola isolar-se da sociedade, já que a escola é, ela mesma, uma instituição da sociedade, uma de suas tarefas, então, é a de debater o esporte, de criticá-lo, de produzí - lo ... e de práticá-lo! [...].14

Nessa linha de análise referente aos conteúdos que são abordados pelos professores, identificamos algumas respostas que nos apresentam a utilização de outros conteúdos que englobam o objeto de estudo da Educação Física, além do esporte. Trabalho todos os conteúdos que estão no planejamento que realizamos para cada série no início do ano de acordo com as diretrizes curriculares (P6B); Procuro trabalhar com jogos e brincadeiras, ginástica, esportes, dança e quando possível lutas também, apesar de considerar um tanto difícil o conteúdo de lutas (P1B); Trabalho com todos os conteúdos considerados clássicos da educação física, como esporte, dança, lutas, jogos e ginástica. No entanto, o percentual de carga horária é maior para o conteúdo esportes. Primeiro, porque são vários esportes; segundo, porque na minha formação foi dado uma ênfase maior neste conteúdo; e terceiro por ter sido atleta, portanto, gosto muito de esportes (P3B).

Diante dessas informações é possível compreendermos a Educação Física a partir de um processo de mudança que pode ir além do rendimento físico e técnico, que muitas vezes acaba sendo veiculado por meio do esporte. A contemplação de outros conteúdos que fazem parte da cultura corporal estimula e incentiva os alunos pela busca de novos conhecimentos, além de superar a insuficiência de um modelo tradicional de ensino pautado somente no desenvolvimento de habilidades motoras.
Nesse sentido, independentemente dos conteúdos que são ensinados para os alunos, devemos considerar o planejamento como um instrumento importante e significativo para o professor de Educação Física escolher as direções para um ensino de qualidade.

Esses elementos são indispensáveis para o tratamento dos conteúdos, para que a metodologia escolhida possa ser efetivada de maneira produtiva no que tange a apreensão dos conhecimentos por parte dos alunos e do desenvolvimento da criticidade diante desses saberes. Nesse sentido, considerando que as estratégias metodológicas utilizadas são fundamentais para um processo de ensino e aprendizagem de qualidade, buscamos perguntar para os professores como eles trabalham os conhecimentos sobre o esporte nas aulas de Educação Física; sendo assim destacamos as seguintes respostas: Primeiro o teórico com o histórico básico, regras, fundamentos, práticas de fundamentos, jogos que possibilitem um contato próximo ao jogo e por fimo jogo em si. (P1A); História do esporte e os fundamentos dos esportes (P3A); Histórico, o jogo, regras, realizando 3 (três) avaliações (P2B); No início do ano é feito o planejamento, neste é colocado um esporte por bimestre, onde é trabalhado a teoria e a prática (P4B); Através de aulas teóricas e práticas, trabalhando dirigidamente o esporte e através de jogos pré-desportivos, jogos e brincadeiras, jogos cooperativos (P6B).

Por meio dessas considerações é possível aproximarmos essas intervenções de algumas abordagens pedagógicas da Educação Física, as quais não são explicitadas pelos professores em relação as estratégias adotadas, mas que se aproximam de algumas concepções a partir das ações que são desempenhadas por esses professores no processo de ensino. A noção de historicidade que é elencada por alguns se torna relevante no sentido de buscar fazer com que os alunos possam perceber esse processo de evolução pelo qual passou a Educação Física na escola por meio de seus conteúdos de ensino. Essas estratégias se caracterizam e se aproximam de uma perspectiva crítica para o ensino da Educação Física, pois de acordo com o Coletivo de Autores, ${ }^{10}$ cada conteúdo dessa área do conhecimento “deve ser estudado profundamente pelo (s) professor (es), desde a sua origem histórica ao seu valor educativo para os propósitos e fins do currículo".

Outra questão bastante abordada pelos professores, enquanto estratégia metodológica adotada para o trabalho com os esportes, foi a presença do jogo como um recurso didático que muitas vezes pode ser:

[...] aplicado para minimizar a atmosfera predominantemente artificial e tecnicista que impera nos meios educacionais. Estimula a crítica, a criatividade, a sociabilização (torna sociável) e a socialização (estende vantagens particulares ao grupo), sendo, portanto, reconhecido como uma das atividades mais significativas - senão a mais significativa - pelo seu conteúdo pedagógico social". ${ }^{13}$

A estratégia metodológica articulada no trabalho com os jogos é muito importante, pois contribui para o desenvolvimento da criticidade e da criatividade dos alunos diante das transformações e mudanças que são reivindicadas, atualmente, no trato pedagógico que 
é dispensado ao conteúdo esporte. No entanto, vários estudos vêm sendo desenvolvidos a respeito do trabalho com os conteúdos da Educação Física e sua relação entre a teoria e a prática no âmbito escolar, os quais são elencados por alguns professores a partir de suas intervenções.

Dessa forma, buscando um diálogo com as representações dos professores, notamos que existe a relação teoria/prática, porém de forma distanciada uma da outra, de um lado os elementos que tratam dos aspectos históricos do esporte e em seguida os jogos que são utilizados para a iniciação de algumas modalidades. Portanto, é importante destacarmos que não é necessário dividir o número de aulas em teóricas ou práticas, mas sim acreditarmos na ideia de que o professor sempre esteja relacionando as duas dimensões no processo educativo, ou seja, que ele desenvolva suas aulas com a ideia da práxis, que é a prática refletida e teorizada de forma irredutível.

Por outro lado referente aos aspectos metodológicos adotados por alguns professores, identificamos a presença de algumas concepções que sustentam e contribuem para o processo de intervenção desses sujeitos, os quais se desenvolvem da seguinte maneira: Através de pesquisas, leituras, debates e discussões de temas específicos; atividades práticas desportivas e construção de novas regras e jogos (P1B); No ensino fundamental é trabalhado a base sobre os fundamentos e no ensino médio a reflexão crítica do mesmo $(P 2 A)$; Eu gosto de despertar o aluno para o meio crítico e isso o jogo proporciona, ele está sempre no processo de ensino aprendizagem. A abordagem crítico-superadora pauta-se para isso (P5B).

Essas estratégias metodológicas adotadas pelos professores apresentam um interesse em pensar a Educação Física além do trabalho com a técnica ou com as habilidades motoras. Na perspectiva dos professores a intenção é que por meio das práticas corporais historicamente construídas, os alunos estejam aptos a refletir criticamente sobre as diversas manifestações da Educação Física e do esporte no contexto da escola, pois conforme Taffarel et al.: ${ }^{15}$

A educação física se caracteriza historicamente pelo trabalho pedagógico da docência no campo da cultura corporal [...] por tratar de um campo de conhecimento que se estrutura a partir das práticas históricas, socialmente produzidas, cientificamente estudadas e investigadas e criativamente ensinadas de geração em geração.

A partir das estratégias elencadas pelos professores no tratamento pedagógico para o ensino do esporte, fica evidente a aproximação de algumas abordagens que se caracterizam como críticas da Educação Física, tais como: a concepção de aulas abertas (1986), sistêmica (1991), crítico-superadora (1992) e crítico-emancipatória (1994), tais abordagens valorizam o diálogo e a ação comunicativa no processo de ensino aprendizagem, bem como a construção de novas propostas de ensino, as práticas históricas, entre outras. No entanto, a abordagem crítico-superadora (CS) na perspectiva de alguns professores, como descreve o (P5B), apresenta uma teoria mais estruturada no que tange o ensino do esporte na escola, "evidenciado-se o sentido e o significado dos valores que inculca e as normas que o regulamentam dentro de nosso contexto sócio-histórico"10

Nessa mesma linha de análise, utilizando-se do mesmo referencial que baliza a abordagem crítico-superadora, temos a manifestação de (P3B), que busca desenvolver suas aulas a partir dos cinco momentos da pedagogia histórico - crítica ${ }^{16,17}$ por acreditar que essa metodologia trabalha além da vivência motora, o conhecimento de várias situações voltadas ao esporte. Trabalho com os cinco momentos da pedagogia histórico - crítica por acreditar que essa metodologia trabalha além da vivência motora, trabalha também o conhecimento de várias situações voltadas ao esporte (P3B). De acordo com Gasparin e Saviani, ${ }^{16,17}$ os cinco momentos são distribuídos da seguinte forma: 1) prática social (diagnóstico do conhecimento da turma sobre o assunto); 2) Problematização (introdução do conteúdo, com diversos questionamentos); 3) Instrumentalização (vivência motora do esporte); 4) Catarse (avaliação do conhecimento adquirido pelo aluno); e 5) Retorno à prática social (comparação com o conhecimento adquirido) (P3B).

Essa estratégia utilizada é muito relevante, pois permite que o aluno se aproprie do esporte não só na sua dimensão técnica e motora, mas também das diversas manifestações que esse conteúdo se articula, enquanto fenômeno multicultural.

Dessa forma, a ordem metodológica para o desenvolvimento das atividades que tratam do esporte seguem os cinco momentos distribuídos da seguinte forma: 1) Prática social que se caracteriza pela apresentação do conteúdo e pelo diagnóstico do conhecimento dos alunos sobre o assunto proposto; 2) Problematização que se caracteriza pela proposição de um desafio, questionamento, obstáculo, cujo propósito é problematizar esse conhecimento advindo da realidade dos alunos; 3) Instrumentalização que se evidencia pela disponibilidade do conhecimento sistematizado para os alunos, por meio da contraposição de saberes (vivência motora do esporte e reflexão sobre a prática); 4) Catarse que se apresenta como um meio para analisar por meio de diversos instrumentos avaliativos, a assimilação dos conhecimentos adquiridos pelos alunos); e 5) Retorno à prática social que se destaca pela comparação e nova leitura da realidade, a partir de todo processo que contribuiu para que o conhecimento fosse adquirido de forma crítica, criativa e transformadora. ${ }^{16}$

Por meio dessa situação explanada, corroboramos com a ideia de Bracht, ${ }^{11}$ o qual nos apresenta que é "preciso analisar o tipo de educação possível, a partir de cada uma das manifestações do esporte, integrando estas análises discursiva e praticamente na concepção pedagógica eleita". No entanto, a Educação Física e a escola por meio de seu projeto político pedagógico, devem apresentar suas propostas de intervenção de forma articulada, visando transformações que podem ocorrer a partir de uma pedagogia crítica, para o ensino do esporte.

Dessa forma, podemos identificar, por meio dos pressupostos teóricos pesquisados e das manifestações dos professores, que apesar da utilização metodológica se apropriar de diferentes formas de intervenção, o objetivo de transmitir o conhecimento com qualidade, torna-se o mesmo, porém, devemos analisar se o caráter subjetivo das informações prestadas está articulado à objetividade das ações, que são necessárias a escola. Nesse sentido, é necessário que o professor anali- 
se a metodologia a ser utilizada nas aulas, a qual inclui a seleção e a organização dos conteúdos de acordo com a faixa etária, o conhecimento da realidade e o contexto dos alunos, entre outros fatores, os quais são fundamentais para fortalecer a ação pedagógica no processo de ensino e aprendizagem no contexto da escola.

\section{O JOGO COMO POSSIBILIDADE DE INTERVENÇÃO PEDAGÓGICA PARA O ENSINO DO ESPORTE}

Essa categoria teve como base as questões que retratam sobre o entendimento dos professores a respeito da diferença entre jogo e esporte e das possibilidades de utilização da estratégia metodológica do jogo para o ensino do esporte. As perguntas levantadas para a discussão foram: Quais as diferenças existentes entre jogo e esporte? e Você acredita que o conteúdo jogo pode contribuir como estratégia metodológica para o ensino do esporte? Por quê?

O jogo e o esporte vêm sendo abordados e pesquisados em suas diferentes perspectivas no intuito de apresentar suas definições, características e suas possibilidades de intervenção em diferentes contextos. Nesse direcionamento, buscamos interpretar por meio das contribuições dos professores, quais são seus entendimentos sobre a relação entre jogo e esporte. Dentre as respostas obtidas apresentamos algumas sob o foco de análise conforme segue: $O$ jogo não possui regras fixas e o esporte em si as regras são fixas $e$ universais (P2A); $O$ jogo é definido como um caráter lúdico com normas livremente estabelecidas pelos praticantes. O esporte por sua vez, tem regras preestabelecidas pelas diferentes instituições que o regem (P1A); Nos jogos não há regras específicas, se define a regra conforme o local e a vontade dos praticantes. Enquanto nos esportes a regra é fixa em qualquer lugar (P3A); Existem várias definições atribuídas por teóricos, porém vou defini-los de forma empírica, ou seja, como eu os classifico em minhas aulas. Esporte: regras definidas e oficializadas. Jogo: a partir do momento que o grupo define as regras eu as adapto (P3B).

Por meio dessas manifestações, podemos identificar que os professores apresentam uma diferenciação entre esses dois conteúdos, compreendendo o jogo como um conteúdo que se evidencia pelas suas regras, mas que podem ser modificadas ou reestruturadas a qualquer momento, buscando aumentar a complexidade da ação dos jogadores a partir da problematização das atividades. Por outro lado, o esporte aparece como um conteúdo que apresenta suas regras de maneira universal, oficializada, compondo um campo de organização burocrática.

No entanto, além das diversas formas de conceituar esses conhecimentos que fazem parte da Educação Física, torna-se necessário compreendermos essa prática e transformá-la no contexto da escola, pois de acordo com Sobrinho: ${ }^{13}$

O jogo na escola tem sido estudado em suas diversas manifestações: enquanto recurso metodológico, enquanto conteúdo de ensino, enquanto método de pesquisa. Ele é capaz de propiciar aprendizagens importantes, como o sentido e significado das regras, como a lógica, como as diferenciações, as nuances e os contrastes necessários para entendermos e explicarmos o mundo.

Para isso, buscamos analisar, a partir da concepção dos professores, as possibilidades e limitações da utilização do jogo como estratégia metodológica para o ensino do esporte, sem intenção de descaracterizá-lo, mas como um subsídio para a ampliação dos saberes por parte da diversidade dos alunos a partir de uma metodologia pautada na ludicidade. Assim, apresentamos algumas contribuições dos professores sob essa perspectiva de intervenção docente por meio do jogo. Sim, pois através do jogo podemos criar inúmeras formas diferenciadas de fazer o aluno vivenciar novas formas de experiências motoras (P2A); Sim, pois ajuda no desenvolvimento integral das crianças e jovens, contribuindo nos aspectos motores, cognitivos, afetivos e sociais (P1A); Sim, pois a minha vivencia é através do jogo que eu dou início as modalidades esportivas (P3A); Sim, o jogo ajuda a desenvolver estratégias para que possamos ensinar o esporte para os alunos (P5B); Sim, através do jogo pode-se chegar a um objetivo, trabalhando de várias maneiras o esporte escolhido. Exemplo: trabalhar os fundamentos através de um jogo pré - desportivo (P6B); Sim, pois os jogos pré - desportivos vão dando base para se aprender determinados esportes, através da aprendizagem das regras (P1B); Sim, quando pensamos na formação de um aluno crítico e criativo, podemos utilizar o jogo como alavanca para atingir esse objetivo (P4B); Acredito que sim, desde que a teoria faça parte do jogo antes de ser praticado $(P 2 B) ;$ Muito, os jogos pré - desportivos é a forma mais democrática e lúdica de ensinar o esporte ( $P 3 B)$.

De forma geral, assim como no questionamento anterior, todos os professores apresentaram a mesma ideia referente à utilização do jogo como uma estratégia para o ensino do esporte, todavia, vale ressaltar, que assim como qualquer outro conteúdo, o esporte deve ser abordado em suas diferentes perspectivas, levando os alunos a compreenderem e refletirem sobre suas diversas manifestações.

O jogo utilizado como um recurso metodológico contribui para que esse processo de aprendizagem seja mais democrático e se torne mais lúdico durante a sistemática de intervenção profissional. Essa definição metodológica se caracteriza por uma concepção que vem sendo estudada por vários autores, sendo a mesma conceituada como pedagogia do esporte. Conforme nos relata Sadi"18 "A pedagogia do esporte como concepção tem como princípio fundamental o ensino (de esporte) por meio de jogos; não qualquer jogo, mas aqueles que se aproximam dos esportes, os jogos esportivos".

Essa opção de intervenção docente por meio de jogos esportivos torna as aulas mais dinâmicas, além de ampliar a capacidade dos alunos de compreenderem o esporte de forma mais sistemática e criativa por meio da transformação e recriação das regras, dos espaços, tempos de aprendizagem e número de participantes. Portanto, é preciso "pensar o esporte" na perspectiva de múltiplas possibilidades, atendendo, tanto as pessoas que o praticam como ocupação de tempo livre, quanto por questões de saúde; enfim, é preciso trabaIhar com a iniciação esportiva que permita aos cidadãos 
uma prática consciente, reflexiva e crítica. ${ }^{19}$

Diante desse posicionamento, identificamos a preocupação de Paes (2001) em pensar em estratégias que possam superar uma visão reduzida e estilizada do esporte; dessa forma, uma proposta pedagógica para o ensino desse conteúdo na escola, deve valorizar suas diferentes dimensões e manifestações, orientados por um processo contextualizado e coerente com as necessidades e dificuldades dos alunos.

Destacamos que esses aspectos metodológicos pautados no jogo para o processo de ensino e aprendizagem do esporte podem contribuir, de forma significativa, para o aprendizado dos alunos, já que por meio dessa articulação, o desenvolvimento da criatividade, da autonomia, da reflexão, entre outros, se tornam mais evidentes e previsíveis durante a ação pedagógica.

\section{CONSIDERAÇÕES FINAIS}

Esperamos com base na pesquisa, que a busca por estratégias metodológicas seja uma constante, e que diante dessas necessidades, as propostas inovadoras possam balizar o tratamento pedagógico para a o trabalho com o esporte, contribuindo dessa forma para o desenvolvimento de uma concepção pedagógica sobre o ensino desse conhecimento na escola.

No que se refere à categoria, conteúdo predominante e estratégias metodológicas utilizadas nas aulas, identificamos uma hegemonia do conteúdo esporte durante o processo de ensino e aprendizagem diante dos outros conteúdos que estruturam o objeto da Educação Física na escola. No entanto, mesmo por meio do esporte, observamos a intenção de alguns sujeitos em trabalhar com a Educação Física, além da dimensão técnica ou somente com o desenvolvimento das habilidades motoras, porém, essas afirmações se distanciam de algumas respostas que são elencadas pelos alunos no desenvolvimento do trabalho, pois ambos denotam a ampla presença dos aspectos direcionados a educação corporal.

Nossa última discussão pautada nas considerações dos professores se destaca pela categoria que trata do jogo como possibilidade de intervenção pedagógica para o ensino do esporte, sendo que, por meio dessa temática, constatamos que os docentes apresentam uma definição e uma diferenciação entre jogo e esporte e que essa proposta pautada em uma perspectiva pedagógica do desporto vem sendo utilizada por esses profissionais, como um recurso metodológico para o trabalho com as modalidades esportivas, proporcionando uma aula mais atraente e participativa, além de ampliar a capacidade dos alunos compreenderem o esporte de forma mais abrangente e sistemática.

Sob essas análises, torna-se necessário articular o objeto de ensino ao contexto social em que a escola está inserida, com o intuito de atender aos interesses dos alunos sobre a prática esportiva, que possa ir além da técnica e performance esportiva.

\section{REFERÊNCIAS}

1. Lopes MRS, Neto ARM, Parente ML da Cruz, Araujo JGE, Souza CB, Moura DL. A prática do planejamento educacional em professores de educação física: construindo uma cultura do planejamento. J Phys Educ 2016;27(2748):1-9. doi: 10.4025/jphyseduc.v27i1.2748

2. Taques MJ. A (des) caracterização do esporte na escola: análise do contexto pedagógico e possibilidades de intervenção. Curitiba, Editora CRV. 2013. 214 p.

3. Thomas J, Nelson J, Silverman S. J. Métodos de pesquisa em atividades físicas. Porto Alegre: Artmed, 2007. 304 p.

4. Bardin L. Análise de Conteúdo. Lisboa: Edições 70, 1977. 280 p.

5. Macedo L. Ensaios Pedagógicos: como construir uma escola para todos? Porto Alegre - RS: Artmed, 2005. 168 p.

6. Bracht V. Esporte de rendimento na escola. In: Stigger MP, Lovisolo H. Esporte de rendimento e esporte na escola. Campinas: Autores Associados, 2009. 218 p.

7. Tubino MJG. Uma visão paradigmática das perspectivas do esporte para o início do século XXI. In: Gebara A, Moreira WW. Educação Física e esportes: perspectivas para o século XXI. Campinas: Papirus, 1992. 260 p.

8. Tubino MJG. Estudos Brasileiros sobre o esporte: ênfase no esporte - educação. Maringá: Eduem, 2010. 163 p.

9. Silva MS, Bracht V. Na pista de práticas e professores inovadores na Educação Física escolar. Revista Kinesis 2012;30(1). doi 10.5902/010283085718

10. Coletivo de autores. Metodologia do ensino de Educação Física. São Paulo: Cortez, 1992. 200 p.

11. Bracht V. Esporte na escola e esporte de rendimento. Revista Movimento, Escola Superior de EF da UFRGS 2000;VI(12):14-24.

12. Vago TM. O "esporte na escola" e o "esporte da escola": da negação radical para uma relação de tensão permanente - um diálogo com Valter Bracht. Revista Movimento 1996; 3(5):4-17.

13. Sobrinho JSFP. $O$ jogo na escola: a oportunidade que eu não tive. In: Taffarel CZ, Hildebrandt-Stramann R. Currículo e Educação Física. Ed. Unijuí. ljuí, 2007. 472 p.

14. Vago TM. O "esporte na escola" e o "esporte da escola": da negação radical para uma relação de tensão permanente - um diálogo com Valter Bracht. Revista Movimento, vol III, Porto Alegre, ano 3, n. 5, p. 4-17, 1996.

15. Taffarel CZ; Hildebrandt-Stramann R. Currículo e Educação Física. Ed. Unijuí. ljuí, 2007. 472 p.

16. Gasparin JL. Uma didática para a pedagogia histórico-crítica. 4 ed. Campinas: Autores Associados, 2007. 212 p.

17. Saviani D. Escola e democracia. 23 ed. São Paulo: Cortez, 1991. $152 \mathrm{p}$.

18. Sadi RS. Pedagogia do esporte: descobrindo novos caminhos. São Paulo: Ícone, 2010. 216 p.

19. Paes RR. Educação Física escolar: o esporte como conteúdo pedagógico do ensino fundamental. Canoas: Ed. Ulbra, 2001. $157 \mathrm{p}$.

Como citar: TAQUES, Marcelo José; MADRID, Silvia Christina de Oliveira. O processo de ensino e aprendizagem do esporte na escola na perspectiva dos professores de Educação Física. Cinergis, Santa Cruz do Sul, v. 18, n. 3, maio 2017. ISSN 2177-4005. Disponíve/ em: <https://online.unisc.br/seer/index.php/cinergis/article/view/8917>. Acesso em: 22 jun. 2017. doi:http://dx.doi. org/10.17058/cinergis. v18i3.8917. 